EPIDEMIOLOGY

\title{
Prevalence and risk factors of chlamydia and gonorrhea among rural Nepali women
}

\author{
P Christian, S K Khatry, S C LeClerq, A A Roess, L Wu, J D Yuenger, J M Zenilman
}

Sex Transm Infect 2005;81:254-258. doi: 10.1136/sti.2004.011817

See end of article for authors' affiliations .....................

Correspondence to: Parul Christian, Department of International Health, The Johns Hopkins Bloomberg School of Public Health, $615 \mathrm{~N}$ Wolfe Street, Room W2041, Baltimore, MD 21205, USA; pchristi@ jhsph.edu

Accepted for publication 12 August 2004

\begin{abstract}
Objectives: The epidemiology of sexually transmitted infections (STI) in rural, developing world populations is poorly understood. We estimated the prevalence and risk factors of Neisseria gonorrhoeae and Chlamydia trachomatis in a female population in rural Nepal.

Methods: We conducted a cross sectional study in a sample of 1177 postpartum women participating in a micronutrient supplementation trial in Nepal. Urine samples were collected to test for the two infections using the ligase chain reaction (LCR).

Results: C trachomatis was detected in 1.0\% (95\% confidence intervals (Cl): 0.4 to 1.5) and $N$ gonorrhoeae in $2.3 \%$ (95\% Cl: 1.2 to 3.4 ) of women. None of the women tested positive for both. Self report of all three symptoms of lower abdominal pain, pain and burning on urination, and vaginal discharge was associated with the presence of gonorrhoea (odds ratio (OR): $12.1,95 \% \mathrm{Cl}: 1.3$ to 115.0 ). Neonatal eye discharge was associated with maternal gonococcal infection $(\mathrm{OR}=5.2,95 \% \mathrm{Cl}$ : 1.1 to 24.9). Incidence of low birth weight was not related to these maternal infections, but very preterm delivery ( $<32$ weeks) was higher among women positive for gonorrhoea $(\mathrm{OR}=4.7,95 \% \mathrm{Cl}$ : 1.0 to 22.0$)$. In a multivariable analysis, low body mass index $(<18.5)$ and cattle ownership were associated with gonorrhoea ( $p<0.05)$, whereas woman's literacy was associated with chlamydia $(p=0.06)$.

Conclusion: We found the rates of $\mathrm{N}$ gonorrhoeae and $\mathrm{C}$ trachomatis to be low among women in this rural population of Nepal.
\end{abstract}

W orldwide more than 340 million cases of sexually transmitted infections (STI) occur each year. ${ }^{1}$ Women and infants with vertically transmitted infection bear the brunt of complications such as stillbirth, ectopic pregnancy, infertility, and ophthalmia neonatorum. Most infected women are asymptomatic and therefore fail to seek timely treatment. ${ }^{2-5}$ STIs also increase the transmission and acquisition risk of HIV-1. ${ }^{6}$ The rapid spread of HIV-1 infection in developing countries has been attributed in part to high STI morbidity as a cofactor. Thus, STI prevention is an integral part of the WHO HIV prevention strategy. ${ }^{7-11}$

HIV prevention policies in south Asia have included the development of HIV/STI sentinel surveillance systems that typically target urban, high risk populations. In contrast, few studies have evaluated STI epidemiology in rural populations. For example, among women who reported to maternal and child health centres in the Matlab area of Bangladesh, the prevalence of Neisseria gonorrhoeae, Chlamydia trachomatis, and active syphilis was $<1 \%{ }^{12}$ In contrast, among urban women examined at antenatal/mother and child health clinics in Pakistan, $\sim 10 \%$ had gonococcal infection. ${ }^{13}$

The present study was conducted in a rural south eastern region of Nepal as part of a trial examining the effects of multiple micronutrients on low birth weight. ${ }^{14}$ In a substudy we tested women at 6 weeks post partum for $N$ gonorrhoeae and $C$ trachomatis using the urine based ligase chain reaction (LCR) method. We describe the prevalence and risk factors for gonococcal and chlamydial infection in this population and examine the risk of low birth weight, preterm delivery, and neonatal eye discharge among infected women.

\section{METHODS}

Study site and population

The parent micronutrient trial ${ }^{14}$ was conducted among 4996 pregnant women from January 1999 through March 2001 in a south eastern rural District of Sarlahi, Nepal. The study area comprised 30 village development communities with $\sim 44000$ women of reproductive age (12-45 years). Details of this study are provided elsewhere. ${ }^{14}$ Briefly, eligible women of reproductive age were registered for pregnancy surveillance and visited at home by project workers every 5 weeks over a period of 12 months. At each visit women who had not menstruated in the past 30 days were given a urine test to detect pregnancy.

Each newly identified pregnant woman was interviewed to obtain data on sociodemographic status, a 30 day recall of morbidity, and alcohol and tobacco use. Morbidity recall included lower abdominal pain, vaginal discharge, and burning or pain upon urination. Anthropometric measurements included weight, height, and mid-upper arm circumference. At 6 weeks post partum, assessment of morbidity and weight measurement was repeated. Home based birth weight was obtained within 72 hours of birth for $80 \%$ of infants. Neonates were visited daily for the first 10 days to ascertain morbidity. On each visit, the newborn's eyes were examined for purulent conjunctivitis. Symptomatic neonates were treated with ciprofloxacin eye drops and ointment using the clinical protocol for treatment currently in use in Nepal.

\section{Substudy}

In nine of the 30 village development communities selected for access to roads, pregnant women were also invited to participate in a substudy which involved intravenous blood sampling at baseline, third trimester, and at 6 weeks post partum. At 6 weeks post partum urine was collected and processed as described below and stored for later testing for chlamydia and gonorrhoea infections. In all, 1177 women who had a live birth were visited at 6 weeks post partum.

Abbreviations: LCR, ligase chain reaction; STI, sexually transmitted infections 
This sample size was sufficient to detect a minimum STI prevalence of $2 \%$ (95\% confidence interval (CI): 1.2 to 2.8 ).

Urine was brought from the field to the study laboratory on ice and processed on the same day. One $\mathrm{ml}$ of urine was transferred into a microfuge tube and centrifuged at $9000 \mathrm{~g}$ for 15 minutes using the Abbott X-Systems high speed centrifuge. The supernatant was discarded and the pellet resuspended in $1.0 \mathrm{ml}$ of the urine resuspension buffer (Roche Diagnostic Systems). The mixture was incubated at $97^{\circ} \mathrm{C}$ in a preheated dry bath for 15 minutes to release the DNA in solution. After cooling the sample was placed in liquid nitrogen for transport to Johns Hopkins University and stored at $-70^{\circ} \mathrm{C}$ until the analysis.

$N$ gonorrhoeae and $C$ trachomatis were detected in the processed urine specimens using the LCR assay (LCx Probe System, Abbott Laboratories, Abbot Park, IL, USA) following the manufacturer's instructions during the autumn of 2001. There have previously been confirmation issues with the LCR test that has resulted in its being withdrawn. Our test lots were obtained before these manufacturing problems, and were also carefully monitored by in-house quality assurance testing. Owing to an expected low prevalence rate of STIs $(<5 \%)$, a pooled urine procedure was used as described by Kacena. ${ }^{15}$ Briefly, LCR testing was performed by pooling four individual samples, with testing of individual specimens done only when the pool was found to be positive. Thus, positive pooled samples were confirmed by a repeat LCR for each individual sample in the pool. Testing was performed at the Johns Hopkins University STD laboratory in Baltimore, MD.

\section{Data analysis}

Because prevalence rates did not differ by nutritional supplementation group, data were pooled for the present analysis. Prevalence of STI infection and 95\% CI were calculated. Univariable analyses were done to examine the associations between infections and individual sociodemographic, obstetric, and other maternal risk factors. Body mass index (weight/height ${ }^{2}$ ) was calculated using weight measured at 6 weeks post partum and height taken at enrolment. Multivariable logistic regression analyses were conducted separately for gonococcal and chlamydial infection using covariates that were found to have large odds ratios $(\mathrm{OR} \geqslant 2.0$

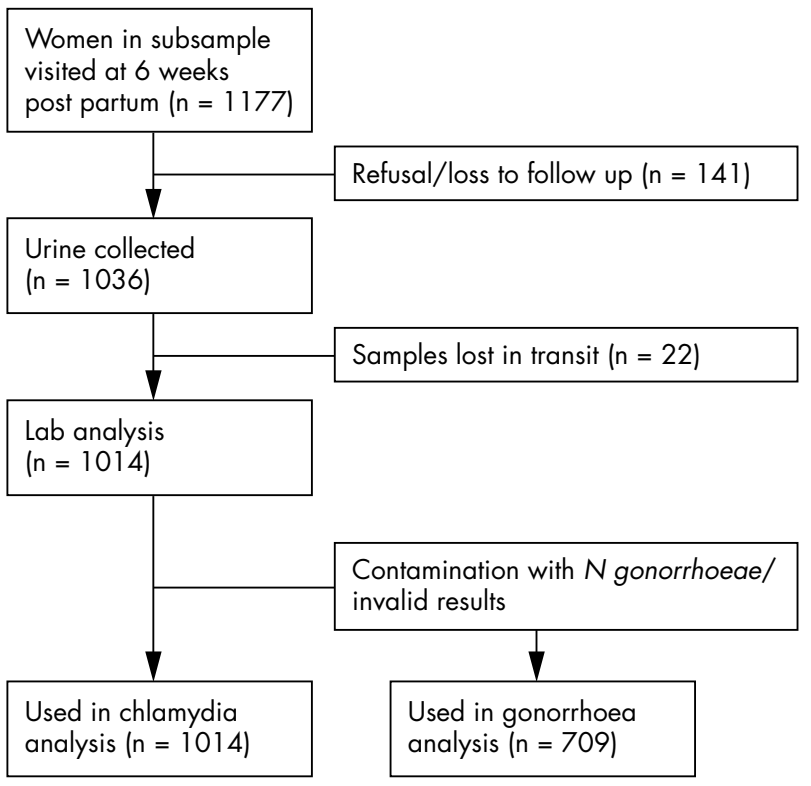

Figure 1 Study participation and follow up. or $\leqslant 0.5$ ) in the univariable analysis, irrespective of whether the $95 \%$ CI included 1. We also retained known risk factors such as age and occupation of the husband in the model. A variable for ethnicity was also included in the final model because of the known differences in the cultural practices of the two major ethnic groups residing in this area. The association between symptoms of lower abdominal pain, vaginal discharge, and painful/burning urination as reported at 6 weeks post partum and clinical infection determined by LCR analysis of maternal urine samples also collected at 6 weeks post partum were examined using OR and 95\% CI. Finally, outcomes of low birth weight $(<2.5 \mathrm{~kg})$, and preterm $(<37$ weeks of gestation) and very preterm delivery ( $<32$ weeks) were examined by whether women were infected or not. All data were analysed using SAS v. 8 (Cary, NC, USA).

\section{Ethical approval}

The study was approved by the Nepal Health Research Council and by the Committee for Human Research at Johns Hopkins. Informed consent was obtained for all study participants.

\section{RESULTS}

Out of 1177, a total of 1014 and 709 urine specimens were available for chlamydia and gonorrhoea testing, respectively (fig 1). About $12 \%$ of women were not met (because they went to their parental home for delivery and temporarily or permanently move out of the study area) or refused urine testing. Among the remainder, $2.1 \%$ of the specimens were lost during transport. A total of 305 specimens were discarded for gonorrhoea testing because laboratory quality assurance procedures identified cross contamination with the gonorrhoea assay. It is unclear if this occurred during specimen transport or at the time of the laboratory analysis. There were no differences in the characteristics of women whose urine specimens were contaminated or not except for a higher prevalence of husband's occupation being business or service in the contaminated group (32.2\% versus $25.4 \%$, $\mathrm{p}=0.03$ ).

Individuals who tested positive were contacted by study personnel and offered treatment. Three of the women had already sought treatment on their own. The others were informed about their results and offered treatment, which was refused. These women were all asymptomatic which may have resulted in their non-acceptance of the treatment. They were advised by the visiting project staff to have a further examination.

The prevalence was $2.3 \%$ (95\% CI: 1.2 to 3.4) (16/709) for $N$ gonorrhoeae and 1\% (95\% CI: 0.4 to 1.5 ) (10/1014) for $C$ trachomatis. None of the women had dual infection. Individual symptoms of lower abdominal pain, painful/ burning urination or vaginal discharge were not associated with $N$ gonorrhoeae, although having all three symptoms, a condition quite rare in the population $(0.6 \%)$, increased by several-fold the risk of being positive (OR $=12.1,95 \%$ CI: 1.3 to 115.0$)$ (table 1). C trachomatis was asymptomatic in nearly all cases.

Neither infection was associated with low birth weight $(<2.5 \mathrm{~kg})$ (table 2$)$. The risk of very preterm delivery ( $<32$ weeks of gestation) was apparently elevated with $N$ gonorrhoeae (OR $=4.7,95 \%$ CI: 1.00 to 22.0 ). Ophthalmia neonatorum diagnosed by symptoms of eye discharge in neonates in the first 10 days of life was strongly associated with $N$ gonorrhoeae $(\mathrm{OR}=5.2,95 \% \mathrm{CI}$ : 1.1 to 24.9$)$ but not $C$ trachomatis.

The multivariable analysis showed few variables to be associated with either infection. Adjusted for other variables, low body mass index (BMI <18.5) was significantly 
Table 1 Association between reported symptoms and presence of gonococcal or chlamydial infection using urine based LCR analysis in women at 6 weeks post partum

\begin{tabular}{|c|c|c|c|c|c|c|}
\hline \multirow[b]{2}{*}{ Symptoms } & \multicolumn{3}{|c|}{ Gonorrhoea } & \multicolumn{3}{|c|}{ Chlamydia } \\
\hline & $\begin{array}{l}\text { Positive } \\
(n=16) \\
(\%)\end{array}$ & $\begin{array}{c}\text { Negative } \\
(n=693) \\
(\%)\end{array}$ & OR $(95 \% \mathrm{Cl})$ & $\begin{array}{l}\text { Positive } \\
(n=10) \\
(\%)\end{array}$ & $\begin{array}{l}\text { Negative } \\
(n=1004) \\
(\%)\end{array}$ & OR $(95 \% \mathrm{Cl})$ \\
\hline Any lower abdominal pain & 13.3 & 11.5 & $1.2(0.3$ to 5.4$)$ & 20.0 & 11.9 & $1.8(0.4$ to 8.8$)$ \\
\hline $\begin{array}{l}\text { Any painful/burning } \\
\text { urination }\end{array}$ & 13.3 & 5.7 & $2.5(0.6$ to 11.6$)$ & 0.0 & 6.0 & \\
\hline Any vaginal discharge & 13.3 & 5.7 & $2.5(0.6$ to 11.6$)$ & 0 & 5.2 & - \\
\hline Any 2 of 3 symptoms & 13.3 & 5.0 & $2.9(0.6$ to 13.5$)$ & & & \\
\hline All 3 symptoms & 6.7 & 0.6 & $12.1(1.3$ to 115.0$)$ & & & \\
\hline
\end{tabular}

Maximum missing data on morbidity for gonorrhoea and chlamydia were 16 and 30 , respectively.

associated with increased odds of $N$ gonorrhoeae, whereas cattle ownership was protective (table 3 ). Maternal literacy appeared to increase the risk of $C$ trachomatis by more than sevenfold $(\mathrm{p}=0.06)$, whereas maternal age, occupation of the husband and tobacco or alcohol use was not associated with the risk of either infection.

\section{DISCUSSION}

We found low rates of gonococcal and chlamydial infection among women in rural Nepal. These rates apply mainly to women in pregnancy or in the early postpartum period when risk of STI is low. Few studies have reported the prevalence and risk factors for STIs in rural populations in south Asia. A majority of studies have focused on urban capitals, and select high risk populations, such as STI clinic attendees, commercial sex workers, and injection drug users. ${ }^{13}{ }^{16-18}$ In one study in rural Bangladesh the prevalence of $N$ gonorrhoeae and $C$ trachomatis was low $(<1 \%) .{ }^{12}$

We used urine based non-invasive nucleic acid amplification test-that is, LCR technology to test for the infections, mainly because the study was community based and acceptability to urine collection was likely to be much higher than for clinical examination. Some cases may be false positive in low prevalence populations using the LCR method, ${ }^{19}$ even though it has relatively high sensitivity compared with cervical specimens. ${ }^{20}$ This problem was overcome in our study by pooling the samples and retesting all individual samples when the pool was found to be positive. There were no gonorrhoea/chlamydia co-infections. This was surprising since co-infection is common in many women who have gonorrhoea. ${ }^{21}{ }^{22}$ The sample size may have been inadequate to detect co-infection given the low prevalence of $C$ trachomatis.

Our study had several limitations. The low prevalence of chlamydial infection affected the precision of its estimate. Secondly, for cultural reasons the questionnaires on risk factors did not include questions on sexual behaviours and other practices that may have been stronger determinants of
STI. Women who were screened for STIs had all recently completed a pregnancy and met the study criteria of being married and living with their husbands. Thirdly, this analysis assumes that in the absence of STI surveillance and treatment in this setting, women who were infected at 6 weeks post partum were also likely to be infected during pregnancy and at the time of delivery. This assumption may be valid as indicated by the increased risk of ophthalmia neonatorum among those positive with $N$ gonorrhoeae at 6 weeks post partum.

\section{Symptoms of STI}

Symptoms of STI did not correlate with urine based LCR testing for STI. This suggests that syndromic treatment guidelines may not be accurate, which has policy implications for testing and treatment of STIs in low prevalence settings. The presence of a single symptom was not predictive. However, we found presence of lower abdominal pain, painful/burning urination, and vaginal discharge was associated with gonococcal but not chlamydial infection. Yet, the sensitivity of self reported clinical symptoms is low. A lack of correlation has previously been reported in Bangladesh, where the WHO syndromic detection of STI was compared with a speculum based method. ${ }^{12}$

\section{Consequences of STI}

Ophthalmia neonatorum was strongly associated with maternal gonococcal infection in a population in which $<1 \%$ of women reported having a caesarean section. The sensitivity of clinical symptoms detected by lay project workers trained to examine eye discharge was low (15\%), although specificity was high $(96 \%)$. From a public health perspective, the prevalence of maternal gonococcal infection determines the frequency of ophthalmia neonatorum, ${ }^{23}$ which in this population was low. Maternal chlamydial infection is also known to cause this condition in neonates, but tends to appear later, which may explain why we found

Table 2 Newborn status and infant mortality by presence of gonorrhoea and chlamydia in women at 6 weeks post partum

\begin{tabular}{|c|c|c|c|c|c|c|}
\hline & \multicolumn{3}{|c|}{ Gonorrhoea $(n=607-707)$} & \multicolumn{3}{|c|}{ Chlamydia $(n=883-1012)$} \\
\hline & $\begin{array}{l}\text { Positive } \\
\text { (\%) }\end{array}$ & $\begin{array}{l}\text { Negative } \\
(\%)\end{array}$ & OR $(95 \% \mathrm{CL})$ & $\begin{array}{l}\text { Positive } \\
\text { (\%) }\end{array}$ & $\begin{array}{l}\text { Negative } \\
(\%)\end{array}$ & OR $(95 \% \mathrm{CL})$ \\
\hline $\begin{array}{l}\text { Low birth weight }(<2.5 \mathrm{~kg}) \\
\text { Preterm delivery (<37 weeks) }\end{array}$ & $\begin{array}{l}46.2 \\
13.3\end{array}$ & $\begin{array}{l}41.3 \\
21.8\end{array}$ & $1.2(0.3$ to 4.3$)$ & $\begin{array}{l}40.0 \\
30.0\end{array}$ & $\begin{array}{l}38.4 \\
20.7\end{array}$ & $1.1(0.2$ to 4.6$)$ \\
\hline $\begin{array}{l}\text { Very preterm delivery } \\
(<32 \text { weeks })\end{array}$ & 13.3 & $\begin{array}{r}21.0 \\
3.2\end{array}$ & $0.6(0.1$ to 2.5$)$ & 10.0 & 3.2 & $34(0.4$ to 27.4$)$ \\
\hline $\begin{array}{l}(<32 \text { weeks) } \\
6 \text { month infant mortality }\end{array}$ & 12.5 & 4.4 & $\begin{array}{l}4.7(1.0 \text { to } 22.0) \\
3.0(0.7 \text { to } 12.5)\end{array}$ & 5) 0 & 4.6 & $\begin{array}{l}0.4(0.41027 .4) \\
-\end{array}$ \\
\hline Eye discharge & 15.4 & 3.4 & $5.2(1.1$ to 24.9$)$ & 0 & 4.4 & - \\
\hline
\end{tabular}


Table 3 Risk factors of gonorrhoea and chlamydia in women at 6 weeks post partum in Nepal

\begin{tabular}{|c|c|c|c|c|c|c|}
\hline & \multicolumn{3}{|c|}{ Gonorrhoea } & \multicolumn{3}{|l|}{ Chlamydia } \\
\hline & $\begin{array}{l}\text { Positive } \\
(n=15) \\
(\%)\end{array}$ & $\begin{array}{l}\text { Negative } \\
\text { (n=653) } \\
(\%)\end{array}$ & $\begin{array}{l}\text { Adjusted OR } \\
(95 \% \mathrm{CI})\end{array}$ & $\begin{array}{l}\text { Positive } \\
(\mathrm{n}=9) \\
(\%)\end{array}$ & $\begin{array}{l}\text { Negative } \\
(\mathrm{n}=939) \\
(\%)\end{array}$ & $\begin{array}{l}\text { Adjusted OR } \\
(95 \% \mathrm{Cl})\end{array}$ \\
\hline Age (years) mean (SD) & $23.1(5.3)$ & $23.6(8.9)$ & $1.0(0.9$ to 1.1$)$ & $24.8(6.4)$ & $23.6(5.8)$ & $1.0(0.2$ to 1.2$)$ \\
\hline Body mass index $* 18.5$ & 53.3 & 27.9 & $3.3(1.1$ to 10.4$)$ & 11.1 & 27.4 & $0.3(0.0$ to 2.5$)$ \\
\hline Tobacco or alcohol use in the past 7 days & 6.7 & 19.9 & $0.2(0.0$ to 1.7$)$ & 33.3 & 20.1 & $3.0(0.6$ to 16.0$)$ \\
\hline Literate-woman & 13.3 & 26.6 & $0.3(0.1$ to 1.8$)$ & 44.4 & 25.4 & $7.4(1.0$ to 56.7$)$ \\
\hline Literate-husband & 60.0 & 54.2 & $2.1(0.6$ to 6.7$)$ & 44.4 & 56.2 & 0.2 (0.0 to 1.7$)$ \\
\hline Business, private or government service $†$ & 26.7 & 26.1 & $0.9(0.3$ to 3.3$)$ & 22.2 & 27.5 & $0.8(0.1$ to 4.2$)$ \\
\hline Cattle ownership & 40.0 & 64.5 & $0.3(0.1$ to 0.9$)$ & 77.8 & 64.2 & $2.1(0.4$ to 11.1$)$ \\
\hline Tiled/tin or cement roofł & 80.0 & 81.5 & $0.9(0.2$ to 3.8$)$ & 88.9 & 82.3 & $2.3(0.2$ to 22.6$)$ \\
\hline Ethnic group (Pahadi)§ & 26.7 & 37.2 & $1.23(0.3$ to 4.8$)$ & 44.4 & 38.8 & $0.7(0.1$ to 3.7$)$ \\
\hline
\end{tabular}

*Body mass index (BMI) is defined as weight $(\mathrm{kg}) / \mathrm{ht}(\mathrm{m})^{2}$

†Compared to farmer or day labourer.

†Compared to no roof or thatched roof.

$\S$ Compared to "Madhesis." Pahadis are peoples who have migrated from the hills to the plains region. Madhesis are migrants from the northern states of India.

no cases of conjunctivitis in the first 10 days of life to be associated with $C$ trachomatis.

In a setting, where prevalence of low birth weight was $43 \%,{ }^{14}$ the contribution of STI to low birth weight or preterm birth may be small, given the low prevalence of infections. And yet, risk of very preterm birth ( $<32$ weeks) was increased by fivefold if women were infected with $N$ gonorrhoeae. Previously both gonococcal ${ }^{24} 25$ and chlamdydial $^{26}{ }^{27}$ infections have been associated with increased risk of preterm birth and low birth weight. In a randomised trial of presumptive therapy for STI during pregnancy in Uganda, significant reductions were observed in neonatal mortality, low birth weight, and preterm delivery. ${ }^{28}$

\section{Risk factors of STI}

The risk factors analysis suffered from low power and should be interpreted with caution. Poor nutritional status at 6 weeks post partum, using low BMI, was independently associated with gonococcal infection. Malnutrition can lower immune function and increase susceptibility to infection. This relation needs further examination. We found no discernible pattern with maternal age unlike in previous studies that have found young age to be associated with increased risk of STI. ${ }^{21} 2930$ In an environment where age at marriage (and first pregnancy) is low, young age may not capture the same risks found in settings where premarital sex is more common.

Despite the low sample size, the risk factors analysis revealed a differing risk pattern between the two STIs as seen in previous studies. ${ }^{31} 32$ Among all the economic status indicators tested, cattle ownership, a proxy indicator of household wealth was the only one that significantly

\section{Key messages}

- Prevalence of gonorrhoea and chlamydia among women in a community based rural area of Nepal is low

- Gonococcal infection was associated with a fivefold increased risk of neonatal eye discharge and very preterm delivery

- Predictive value of clinical symptoms was low raising the issue of timely detection and treatment of STIs

- In this low prevalence setting, usual risk factors such as age are unlikely to be associated with risk of infection increased the protective odds of $N$ gonorrhoeae, maybe because socioeconomic differences are less variable in this predominantly agricultural community. The types of risk factors that influence STI risk in this low risk environment need better understanding.

In conclusion, we present some of the first population based estimates of the prevalence of STI among rural, Nepali women who had a recent pregnancy. The study also revealed the problem of detecting STI in the absence of sensitive and specific point of care rapid tests and showed that the usual risk factors such as age are unlikely to be useful for improving the predictive value of the clinical symptoms.

\section{ACKNOWLEDGEMENTS}

The study was carried out under cooperative agreement HRN-A-0097-00015-00 between the Office of Health and Nutrition, USAID, Washington DC, and the Center for Human Nutrition at Johns Hopkins Bloomberg School of Public Health, Baltimore, MD. Additional support was provided by the Bill and Melinda Gates Foundation, Seattle, WA, and Task Force Sight and Life Research Institute, Baltimore, MD, and UNICEF Office, Nepal. Supplements were produced by Roche, Brazil, and NutriCorp International, CE Jameison, Ontario, Canada. Support from NIH Grant K24AI01633 is also acknowledged.

Apart from the authors, the following members of the Nepal study team helped in the successful implementation of the study: Sharada R Shrestha, Tirtha Raj Shakya, Rabindra Shrestha, Uma Shankar Sah, Arun Bhetwal, Gokarna Subedi, and Dhrub Khadka; Prasad Podas who assisted with the training and supervision of urine collection and processing in the field; Keith P West Jr, Joanne Katz, Elizabeth K Pradhan, and Dean Alfred Sommer for their contributions to study design, implementation and interpretation of data; Gwendolyn Clemens for computer programming and data management; Ravi Ram, Seema Rai, and Sunita Pant for data cleaning and supervision.

\section{CONTRIBUTORS}

PC was the principal investigator; SKK was the project director and was responsible for study implementation; SCL assisted with quality control, forms and procedures for the study; AR helped with the LCR analysis and manuscript preparation; LW assisted with the statistical analysis; JDY oversaw the training for the urine processing and LCR analysis; JMZ helped with editing the manuscript and interpretation of the results.

\section{Authors' affiliations}

P Christian, S C LeClerq, A A Roess, L Wu, Department of International Health, Bloomberg School of Public Health, The Johns Hopkins University, Baltimore, MD, USA

S K Khatry, Society for Prevention of Blindness, Tripureswor, Kathmandu, Nepal 
J D Yuenger, J M Zenilman, Infectious Diseases Division, School of Medicine, The Johns Hopkins University, Baltimore, MD, USA

There are no competing interests to declare.

\section{REFERENCES}

1 World Health Organization. Global prevalence and incidence of selected curable sexually transmitted infections. Overview and estimates. Geneva: WHO, 2001.

2 Bogaerts J, Ahmed A, Akhter N, et al. Sexually transmitted infections in a basic healthcare clinic in Dhaka, Bangladesh: syndromic management for cervicitis is not justified. Sex Transm Infect 1999;75:437-8.

3 Hawkes S, Morison L, Mabey D, et al. STD research and policy formulation. Lancet 2000;355:1275-6.

4 Wasserheit JNH, Harris JR, Chakraborty JR, et al. Reproductive tract infections in a family planning population in rural Bangladesh. Stud Fam Plann 1989;20:69-80

5 Wasserheit JNH. The significance and scope of reproductive tract infections among third world women. Int J Gynaecol Obstet 1989:3:S1 45-68.

6 Wasserheit JNH. Epidemiological synergy: inter relationships between HIV infection and other STDs. Sex Transm Dis 1992;19:61-77.

7 Brunham R, Embree JE. Sexually transmitted infections in the third world: current and future dimensions of the problem in the third world. In: Germain KHA, Piot P, Wasserheit JN, eds. Reproductive tract infections: global impact and priorities for women's reproductive health. New York, NY: Plenum Press, 1992:35-58

8 Kumar B, Handa B, Malhorta S. Changing trends of sexually transmitted diseases. Int J STD AIDS 1995; 16:24-7.

9 Islam M, Mitra AK, Mian AH, et al. HIV/AIDS in Bangladesh: a national surveillance. Int I STD AIDS 1999;10:471-4.

10 De Francisco A. STD research and policy formulation. Lancet 2000;355:1276.

11 Rasheed F, Karim E. STD research and policy formulation. Lancet 2000;355:1275.

12 Hawkes S, Morison L, Foster S, et al. Reproductive tract infections in women in low-income, low-prevalence situations: assessment of syndromic management in Matlab, Bangladesh. Lancet 1999;354:1776-81.

13 Anwar T, Cuevas LE, Shears P. Neisseria gonorrhoeae infection among pregnant women in Peshawar, Pakistan: prevalence and risk factors. Trop Doc 2000;30:81-4

14 Christian P, Khatry SK, Katz J, et al. Effects of alternative maternal micronutrient supplements on low birth weight in rural Nepal: double blind randomized community trial. BMJ 2003;326:571-6.

15 Kacena KA, Qninn SB, Howell MR, et al. Pooling urine samples for ligase chain reaction screening for genital Chlamydia trachomatis infection in asymptomatic women. J Clin Microbiol 1998;36:481-5.

16 Oelrichs RB, Shrestha IL, Anderson DA, et al. The explosive human immunodeficiency virus type 1 epidemic among injecting drug users of
Kathmandu, Nepal, is caused by a subtype $C$ virus of restricted genetic diversity. J Viro 2000;74:1149-57.

17 Caldwell B, Pieris I, Barkat-e-Khuda, et al. Sexual regimes and sexual networking: the risk of an HIV/AIDS epidemic in Bangladesh. Soc Sci Med 1999:48: 1103-16.

18 Divekar AA, Gogate AS, Shivkar LK, et al. Disease prevalence in women attending the STD clinic in Mumbai (formerly Bombay), India. Int J STD AIDS 2000;11:45-8.

19 Zenilman JM, Miller WC, Gaydos C, et al. LCR testing for gonorrhoea and chlamydia in population surveys and other screenings of low prevalence populations: coping with decreased positive predictive value. Sex Transm Infect 2003;79:94-7.

20 Peralta L, Durako SJ, Ma Y. Adolescent Medicine HIV/AIDS Research Network. Correlation between urine and cervical specimens for the detection of cervical Chlamydia trachomatis and Neisseria gonorrrhoeae using ligase chain reaction in a cohort of HIV infected and uninfected adolescents. $J$ Adolesc Health 2001; 29:S87-92.

21 Dicker LW, Mosure DJ, Berman SM, et al. Gonorrhea prevalence and coinfection with chlamydia in women in the United States, 2000. Sex Transm Dis 2003;30:472-6. 22 Lyss SB, Kamb ML, Peterman TA, et al. Chlamydia trachomatis among transmitted disease clinics in the United States. Ann Intern Med 2003:139:178-85.

23 Laga M, Meheus A, Piot P. Epidemiology and control of gonococcal opthalmia neonatorum. Bull World Health Organ 1989;67:471-7.

24 Elliott B, Brunham RC, Laga $M$, et al. Maternal gonococcal infection as a preventable risk factor for low birth weight. J Infect Dis 1990;161:531-6.

25 Donders GG, Desmyter J, De Wet DH, et al. The association of gonorrhoea and syphilis with premature birth and low birthweight. Genitourin Med 1993;69:98-101.

26 Claman P, Toye B, Peeling SW, et al. Serologic evidence of Chlamydia trachomatis infection and risk of preterm birth. Can Med Assoc J 1995:153:259-62.

27 Rastogi S, Das B, Salhan S, et al. Effect of treatment for Chlamydia trachomatis during pregnancy. Int I Gynaecol Obstet 2003;80:129-37.

28 Gray RH, Wabwire-Mangern F, Kigozi G, et al. Randomized trial of presumptive sexually transmitted disease therapy during pregnancy in Rakai, Uganda. Am J Obstet Gynecol 2001;185:1209-17.

29 Chout RT, Vaton S, Duval-Violton D, et al. Screening for Chlamydia trachomatis infection in pregnant women in Marinique. Sex Transm Dis 1995;22:221-7.

30 Sullivan EA, Abel M, Tabrizi S, et al. Prevalence of sexually transmitted infections among antenatal women in Vanuatu, 1999-2000. Sex Transm Dis 2003;30:362-6.

31 Zimmerman HL, Potterat JJ, Dukes RL, et al. Epidemiologic differences between clamydia and gonorrhea. Am J Public Health 1990;80:1228-42.

32 Jolly AM, Orr PH, Hammond G, et al. Risk factors for infections in women undergoing testing for Chlamydia trachomatis and Neisseria gonorrhoeae in Manitoba, Canada. Sex Transm Dis 1995;22:289-95. 